\title{
PENGOPTIMALAN BIAYA DISTRIBUSI BERAS MISKIN DI PERUSAHAAN UMUM BADAN URUSAN LOGISTIK DIVIS REGIONAL SULAWESI UTARA DAN GORONTALO DENGAN MENGGUNAKAN METODE PENDEKATAN VOGEL
}

\author{
Raynaldi Yudha Pratama ${ }^{1)}$, Marline Paendong ${ }^{1)}$, Winsy Weku ${ }^{1)}$ \\ ${ }^{1)}$ Program Studi Matematika, Fakultas Matematika dan Ilmu Pengetahuan Alam, \\ Universitas Sam Ratulangi Manado \\ e-mail : raypratama3@gmail.com; marline.paendong16@gmail.com; winsyweku@gmail.com
}

\begin{abstract}
ABSTRAK
Raskin merupakan salah satu dari berbagai program pemerintah Indonesia yang bertujuan untuk meningkatkan ketahanan pangan nasional melalui penyaluran beras bersubsidi bagi rumah tangga miskin. Dalam pelaksanaannya, raskin memiliki tim koordinasi yang terdiri dari beberapa lembaga negara di mana salah satunya Perusahaan Umum Badan Urusan Logistik (Perum Bulog).Penelitian ini bertujuan untuk mengoptimalkan biaya distribusi beras miskin di Sulawesi Utara dari 5 gudang ke 15 tujuan selama tahun 2016 . Penelitian ini dilakukan di perusahaan Umum Badan Urusan Logistik Divisi Regional Sulawesi Utara dan Gorontalo. Adapun kegunaan dari penelitian ini untuk mengatur alokasi pendistribusian beras miskin perusahaan sehingga mendapat biaya yang optimal. Metode analisis yang digunakan adalah menggunakan metode pendekatan vogel. Dari hasil penelitian dan perhitungan dengan program riset operasi diperoleh hasil bahwa perusahaan mengeluarkan biaya distribusi beras miskin selama tahun 2016 sebesar Rp.5.282.261.280.
\end{abstract}

Kata Kunci: Metode Pendekatan Vogel, Beras Miskin, Sulawesi Utara, Gorontalo.

\section{THE OPTIMIZATION OF BERAS MISKIN DISTRIBUTION COSTS IN THE PUBLIC LOGISTICS COMPANY, REGIONAL DIVISION OF NORTH SULAWESI AND GORONTALO USING VOGEL APPROXIMATION METHOD}

\begin{abstract}
Beras miskin is one of the Indonesia government programs that aim to increase the endurance of national food through subsidized rice for the poor. In the case of realization, Beras miskin has several state institutions that included to manage it, one of them is the public logistics company. This research aims to optimize the distribution costs of Beras miskin in North Sulawesi from 5 warehouses to 15 destinations during 2016. This research has been done at The Public Logistics company, Regional Division of North Sulawesi and Gorontalo. The purpose of this research is to manage the company's to distribute Beras Miskin with optimal cost. The Method that used in this research is Vogel approximation Method. The results of this research is the company expel the distribution costs of Beras miskin during 2016 amounts Rp.5.282.261.280.
\end{abstract}

Keywords: Vogel Approximation Method, Beras Miskin, North Sulawesi, Gorontalo

\section{PENDAHULUAN}

Raskin merupakan salah satu dari berbagai program pemerintah Indonesia yang bertujuan untuk meningkatkan ketahanan pangan nasional melalui penyaluran beras bersubsidi bagi rumah tangga miskin. Dalam pelaksanaannya, raskin memiliki tim koordinasi yang terdiri dari beberapa lembaga negara di mana salah satunya Perusahaan Umum Badan Urusan Logistik (Perum Bulog). Perum Bulog sebagai salah satu lembaga negara yang memiliki wewenang dalam hal penanganan kebutuhan pangan 
pokok dalam negeri memiliki beberapa program kerja yang salah satunya adalah melakukan pendistribusian beras untuk rumah tangga miskin. Pendistribusian raskin dilakukan dari gudang Bulog ke titik-titik distribusi yang ditunjuk pada tiap-tiap kabupaten/kota.

Mengetahui betapa pentingnya pendistribusian yang tepat, maka penulis tertarik untuk melakukan penelitian dan evaluasi terhadap penyaluran distribusi raskin di Sulawesi Utara yang di bawahi oleh Perum Bulog Divisi Regional Sulawesi Utara \& Gorontalo untuk mencari solusi optimal agar biaya distribusi raskin merata dan tepat, dimana penulis menggunakan metode transportasi untuk mengolah data dan mencari biaya pendistribusian raskin dengan pemilihan jalur distribusi yang tepat dengan tujuan agar biaya pendistribusian raskin perusahaan selama tahun 2016 yang diperoleh optimal sehingga masalah pendistribusian raskin di Perum Bulog Divisi Regional Sulawesi Utara \& Gorontalo dapat terselesaikan.

\section{TINJAUAN PUSTAKA}

Simbolon, dkk (2014) "Aplikasi Metode Transportasi Dalam Optimasi Biaya Distribusi Beras Miskin (raskin) Pada Perum Bulog Sub Divre Medan". Penelitian ini dilakukan pada Perum Bulog Sub Divre Medan yang merupakan lembaga pelaksana program beras miskin (raskin) untuk beberapa kabupaten dan Kota di Sumatra Utara. Penelitian ini bertujuan untuk mengetahui apakah metode transportasi dapat memberi penghematan atau efisiensi biaya distribusi raskin. Pengoptimalan biaya distribusi dalam penelitian ini menggunakan metode pendekatan vogel yang mana dipakai oleh peneliti karena metode tersebut lebih mudah dan cepat dibanding metode lainnya. Penelitian ini menghasilkan biaya distribusi raskin optimum yang lebih rendah dari perhitungan perusahaan, di mana biaya yang diperoleh dengan metode transportasi sebesar Rp.954.800.485,30 sedangkan biaya dari perhitungan perusahaan sebesar Rp.958.073.750,40, dengan demikian penggunaan metode transportasi dapat menghemat biaya distribusi raskin sebesar Rp.3.273.265,10.
Nelwan, dkk (2013) "Optimasi Pendistribusian Air Dengan Menggunakan Metode Least Cost Dan Metode Modified Distribution". Penelitian ini membahas pengoptimalan distribusi Air di PDAM Minahasa Utara dengan menggunakan metode Least Cost dan metode Modified Distribution. Hasil penelitian menunjukkan bahwa biaya operasional yang dikeluarkan sebelum dilakukan minimalisasi yaitu $\mathrm{Rp}$. 603.364.240 dan biaya operasional yang dikeluarkan setelah diminimalisasi menggunakan metode Least Cost yaitu Rp. 588.814.656.

Berdasarkan penelitian sebelumnya penulis tertarik menerapkan metode transportasi khususnya dalam hal meminimumkan biaya distribusi raskin di Perum Bulog Divisi Regional Sulawesi Utara \& Gorontalo, dimana berdasarkan hasil perhitungan perusahaan selama tahun 2016 biaya distribusi raskin yang dikeluarkan perusahaan cukup besar yakni Rp. 5.282.261.280, untuk itu dengan menggunakan metode pendekatan vogel dengan tujuan untuk mengatur alokasi raskin dari beberapa gudang ke sejumlah daerah tujuan yang membutuhkan, penulis akan menganalisa berbagai data distribusi perusahaan agar dapat memperoleh hasil biaya distribusi yang lebih optimal.

\section{Riset Operasi}

Riset operasi (Operation Research/OR) berusaha menetapkan arah tindakan terbaik (Optimum) dari sebuah masalah keputusan di bawah pembatasan sumber daya yang terbatas. Istilah riset operasi sering kali diasosiasikan hampir secara eksklusif dengan penggunaan teknikteknik matematis untuk membuat model dan menganalisis masalah keputusan. (Taha, 1996).

\section{Program Linier}

Program linier adalah salah satu model matematika yang digunakan untuk menyelesaikan masalah optimisasi, yaitu memaksimumkan atau meminimumkan fungsi tujuan yang bergantung pada sejumlah variabel input. (Yuwono, 2007) 


\section{Model Transportasi}

Metode Transportasi merupakan suatu metode yang digunakan untuk mengatur distribusi dari sumber-sumber yang menyediakan produk yang sama ke tempattempat yang membutuhkan secara optimal dengan biaya yang termurah. (Kertiasih, 2009)

Metode transportasi adalah suatu bentuk khusus untuk mempermudah metode simpleks. Nama tersebut diambil dari kegunaan metode tersebut yang meliputi masalah-masalah angkutan dari beberapa sumber ke beberapa tujuan. Dua hal objek mendasar dalam masalah ini yaitu: (Chase et al, 2004)

1. Minimasi ongkos angkut, $\mathrm{n}$ unit ke $\mathrm{m}$ tujuan.

2. Maksimalisasi laba angkut, $n$ unit ke $m$ tujuan.

Metode transportasi berhubungan dengan distribusi suatu produk tunggal dari beberapa sumber dengan penawaran terbatas, menuju beberapa tujuan, dengan permintaan tertentu, pada biaya distribusi minimum. (Aminudin, 2005)

\section{Formulasi Masalah Transportasi}

Secara matematis permasalahan transportasi dapat diformulasikan sebagai berikut:

Fungsi tujuan:

$$
\text { minimumkan } Z=\sum_{i=1}^{m} \sum_{j=1}^{n}=C_{i j} X_{i j}
$$

dengan batasan :

$$
\begin{aligned}
& \sum_{j=1}^{n} X_{i j} \leq S_{i} \quad i=1,2, \ldots, n \\
& \sum_{i=1}^{m} X_{i j} \geq D_{j} \quad j=1,2, \ldots, m \\
& x_{i j} \geq 0, \quad \text { untuk semua } i \text { dan } j \\
& i=\text { sumber }, \mathrm{j}=\text { tujuan }
\end{aligned}
$$

Kelompok batasan pertama menetapkan bahwa jumlah pengiriman dari sebuah sumber tidak dapat melebihi penawarannya, begitu juga dengan kelompok batasan kedua yang menetapkan bahwa jumlah pengiriman ke sebuah tujuan harus memenuhi permintaannya.

$$
\text { Masalah transportasi dapat }
$$

ditempatkan dalam suatu tabel khusus yang dinamakan tabel transportasi. Dalam tabel transportasi terdapat $m x n$ kotak. Biaya transportasi per unit barang $C_{i j}$ dicatat pada kotak kecil di bagian kanan atas setiap kotak. Permintaan dari setiap tujuan terdapat pada baris paling bawah, sementara penawaran setiap sumber dicatat pada kolom paling kanan. Kotak pojok kiri bawah menunjukkan kenyataan bahwa penawaran atau supply $(S)$ sama dengan permintaan atau demand $(D)$. Variabel $X_{i j}$ pada setiap kotak menunjukkan jumlah barang yang diangkut dari sumber $i$ ke tujuan $j$.

\section{Kesetimbangan Model Transportasi}

Pada kenyataannya bahwa jumlah yang di suplai tidak sama dengan permintaannya, dapat lebih besar atau lebih kecil. Kondisi tersebut tidak setimbang. Kondisi tidak setimbang harus dibuat setimbang dengan menambahkan sumber/tujuan yang besifat dummy. Jika supply > demand, tambahkan tujuan dummy untuk menerima sejumlah barang yang ditawarkan dari sumber. Jika supply < demand, tambahkan sumber dummy untuk menerima sejumlah kebutuhan jumlah barang yang diminta atau di pesan oleh tujuan. (Jevi dan Hendi, 2012).

\section{Pemecahan Masalah Transportasi}

Metode ini menggunakan langkahlangkah metode simpleks secara langsung dan hanya berbeda dalam perincian penerapan kondisi optimalitas dan kelayakan.

\section{Menentukan Solusi Fisibel A wal}

Langkah pertama untuk menyelesaikan masalah transportasi adalah dengan menentukan solusi fisibel awal, ada tiga metode antara lain:
1. Metode Pojok Barat Laut (North West Corner)

2. Metode Biaya Terendah (Least Cost)

3. Metode Pendekatan Vogel (Vogels Approximation Method/VAM)

\section{Menentukan Solusi Optimal}

Setelah mendapatkan solusi fisibel awal maka selanjutnya dicari solusi optimal. Ada dua metode untuk mencari solusi optimal antara lain:

1. Metode Modified Distribution (MODI)

2. Metode Stepping Stone 


\section{METODOLOGI PENELITIAN}

Analisis penelitian ini di selesaikan dalam waktu kurang lebih 4 (empat) bulan. Dimulai dari bulan Februari 2017 sampai dengan selesai pada Bulan Mei 2017. Tempat pelaksanaan penelitian di Perusahaan Umum Badan Urusan Logistik Divisi Regional Sulawesi Utara dan Gorontalo yang beralamatkan di Jl. Diponegoro, Lawangirung, Wenang, Kota Manado.

\section{Objek Penelitian}

Variabel yang digunakan dalam penelitian ini antara lain:

1. Persediaan raskin di gudang selama tahun 2016

2. Penyaluran raskin dari gudang ke sejumlah tujuan selama tahun 2016

3. Tarif angkut $(\mathrm{Rp} / \mathrm{kg})$ raskin dari gudang ke sejumlah tujuan

\section{Data Yang Digunakan}

1. Data kuantitatif yaitu data yang diperoleh dari perusahaan dalam bentuk angkaangka mengenai data bulanan selama tahun 2016 mencakup data penyaluran raskin, persediaan raskin dan data tarif angkut raskin yang didistribusikan ke daerah tujuan

2. Data kualitatif yaitu data yang diperoleh dari perusahaan dalam bentuk informasi baik lisan maupun tulisan yang sifatnya bukan angka, yaitu informasi mengenai sumber (gudang raskin), daerah tujuan pendistribusian, bagian proses distribusi, dan metode transportasi yang digunakan.

Data-data tersebut sebagaimana pada tabel 1 , 2, dan 3 .

Tabel 1. Jumlah Persediaan Raskin Selama Tahun 2016

\begin{tabular}{|c|c|c|}
\hline No & Gudang & Jumlah Raskin (Kg) \\
\hline 1 & Bitung & $139.712 .244,76$ \\
\hline 2 & Tahuna & $10.402 .581,00$ \\
\hline 3 & Siau & $2.199 .932,00$ \\
\hline 4 & Beo,Melonguane,Lirung & $8.521 .537,00$ \\
\hline 5 & Kotamobagu & $20.250 .907,35$ \\
\hline
\end{tabular}

Tabel 2. Penyaluran Raskin Selama Tahun 2016

\begin{tabular}{|c|c|c|c|}
\hline No & Gudang & Tujuan & Jumlah Beras (kg) \\
\hline \multirow{7}{*}{1} & \multirow{7}{*}{ Bitung } & Manado & 2.892 .060 \\
\hline & & Mitra & 1.627 .020 \\
\hline & & Tomohon & 980.100 \\
\hline & & Minahasa & 3.897 .900 \\
\hline & & Minahasa Utara & 2.965 .320 \\
\hline & & Minahasa Selatan & 3.513 .060 \\
\hline & & Bitung & 1.943 .640 \\
\hline 2 & Tahuna & Sangihe & 1.920 .780 \\
\hline 3 & Siau & Sitaro & 1.644 .660 \\
\hline 4 & $\begin{array}{c}\text { Beo } \\
\text { Melonguane } \\
\text { Lirung } \\
\end{array}$ & Talaud & 458.280 \\
\hline \multirow{5}{*}{5} & \multirow{5}{*}{ Kotamobagu } & Kotamobagu & 1.101 .960 \\
\hline & & Boltim & 788.400 \\
\hline & & Bolmut & 853.020 \\
\hline & & Bolsel & 1.004 .400 \\
\hline & & Bolmong & 3.405 .420 \\
\hline
\end{tabular}

\section{HASIL DAN PEMBAHASAN}

Berdasarkan data yang diperoleh dari perusahaan umum badan urusan logistik divisi regional Sulawesi Utara dan Gorontalo di buat tabel berdasarkan data tarif angkut raskin selama tahun 2016 beserta dengan persediaan (supply) raskin dan permintaan (demand) raskin dari 5 gudang (Bitung, Tahuna, Siau, Beo,Melonguane, Lirung, dan Kotamobagu) ke 15 tujuan selama tahun 2016.

Pada distribusi penyaluran beras miskin tahun 2016 terdapat tarif angkut beras miskin yang paling murah dimana untuk setiap kilogram berasnnya sebesar Rp. 162, hal utama yang menyebabkan tarif angkut tersebut murah yakni jarak jalur pendistribusiannya yang dekat. Berikut merupakan jalur pendistribusian raskin dengan biaya termurah: 
Tabel 3. Tarif Angkut Raskin Dari Gudang Ke Tujuan $(\mathrm{Rp} / \mathrm{Kg})$

\begin{tabular}{|c|c|c|c|c|}
\hline Dari/ke & Manado & Mitra & Tomohon & Minahasa \\
\hline Bitung & 162 & 204 & 162 & 189 \\
\hline Tahuna & 250 & 265 & 250 & 265 \\
\hline Siau & 245 & 255 & 245 & 250 \\
\hline $\begin{array}{c}\text { Beo } \\
\begin{array}{c}\text { Melonguane } \\
\text { Lirung }\end{array} \\
\end{array}$ & 223 & 240 & 255 & 260 \\
\hline Kotamobagu & 210 & 206 & 208 & 206 \\
\hline Dari/ke & Minut & Minsel & Bitung & Sangihe \\
\hline Bitung & 168 & 200 & 162 & 250 \\
\hline Tahuna & 250 & 260 & 250 & 204 \\
\hline Siau & 250 & 250 & 245 & 204 \\
\hline $\begin{array}{c}\text { Beo } \\
\begin{array}{c}\text { Melonguane } \\
\text { Lirung }\end{array} \\
\end{array}$ & 224 & 229 & 223 & 208 \\
\hline Kotamobagu & 208 & 206 & 210 & 270 \\
\hline Dari/ke & Sitaro & Talaud & Kota & Boltim \\
\hline Bitung & 250 & 255 & 210 & 211 \\
\hline Tahuna & 205 & 206 & 270 & 272 \\
\hline Siau & 189 & 205 & 271 & 270 \\
\hline $\begin{array}{c}\text { Beo } \\
\begin{array}{c}\text { Melonguane } \\
\text { Lirung }\end{array} \\
\end{array}$ & 205 & 204 & 220 & 271 \\
\hline Kotamobagu & 271 & 270 & 162 & 189 \\
\hline Dari/ke & Bolmut & Bolsel & Bolmong & \\
\hline Bitung & 211 & 213 & 210 & \\
\hline Tahuna & 275 & 271 & 203 & \\
\hline Siau & 275 & 276 & 273 & \\
\hline $\begin{array}{c}\text { Beo } \\
\begin{array}{c}\text { Melonguane } \\
\text { Lirung }\end{array} \\
\end{array}$ & 277 & 276 & 275 & \\
\hline Kotamobagu & 204 & 200 & 168 & \\
\hline
\end{tabular}

1. Gudang Bitung ke Manado

2. Gudang Bitung ke Tomohon

3. Gudang Bitung ke Bitung

4. Gudang Kotamobagu ke Kotamobagu

Selain tarif angkut dapat diamati pula supply (kapasitas gudang) dan demand (permintaan) yang paling besar, yaitu gudang Bitung memiliki kapasitas penyimpanan beras miskin terbesar selama tahun 2016 yakni $139.712 .244,76 \mathrm{~kg}$, hal yang mempengaruhi besarnya kapasitas yaitu karena gudang Bitung dekat dengan pelabuhan utama. Selain itu untuk permintaan beras miskin terbesar selama tahun 2016 terletak pada daerah tujuan Minahasa yakni sebesar $3.897 .900 \mathrm{~kg}$, hal utama yang mempengaruhi besarnya permintaan adalah wilayah Minahasa yang luas diikuti dengan jumlah penduduk kurang mampu yang besar pula. Rincian tarif angkut beras miskin, supply dan demand sebagaimana pada tabel 4 .

Tabel 4. Tarif Angkut Raskin Beserta Supply dan Demand Masing-Masing Gudang dan Tujuan

\begin{tabular}{|c|c|c|c|c|c|}
\hline \multirow[b]{2}{*}{ Darike } & \multicolumn{4}{|c|}{ Tarif Angkut Raskin (Rp/Kg) } & \multirow[b]{2}{*}{ Supply(Kg) } \\
\hline & Manado & Mitra & Tomohon & Minahasa & \\
\hline Bitung & 162 & 204 & 162 & 189 & $139.712 .244,76$ \\
\hline Tahuna & 250 & 265 & 250 & 265 & $10.402 .581,00$ \\
\hline Siau & 245 & 255 & 245 & 250 & $2.199 .932,00$ \\
\hline $\begin{array}{c}\text { Beo } \\
\text { Melong } \\
\text { Lirung }\end{array}$ & 223 & 240 & 255 & 260 & $8.521 .537,00$ \\
\hline Kotamobagu & 210 & 206 & 208 & 206 & $20.250 .907,35$ \\
\hline \multirow[t]{2}{*}{ Demand(Kg) } & 2.892 .060 & 1.627 .020 & 980.100 & 3.897 .900 & \\
\hline & \multicolumn{4}{|c|}{ Tarif Angkut Raskin (Rp/Kg) } & \\
\hline Darike & Minut & Minsel & Bitung & Sangihe & Supply(Kg) \\
\hline Bitung & 168 & 200 & 162 & 250 & $139.712 .244,76$ \\
\hline Tahuna & 250 & 260 & 250 & 204 & $10.402 .581,00$ \\
\hline Siau & 250 & 250 & 245 & 204 & $2.199 .932,00$ \\
\hline $\begin{array}{c}\text { Beo } \\
\text { Melong } \\
\text { Lirung } \\
\end{array}$ & 224 & 229 & 223 & 208 & $8.521 .537,00$ \\
\hline Kotamobagu & 208 & 206 & 210 & 270 & $20.250 .907,35$ \\
\hline \multirow[t]{2}{*}{ Demand(Kg) } & 2.965 .320 & 3.513 .060 & 1.943640 & 1920780 & \\
\hline & \multicolumn{4}{|c|}{ Tarif Angkut Raskin (Rp/Kg) } & \\
\hline Darike & Talaud & Sitaro & Kota & Boltim & $\operatorname{Supply}(\mathrm{Kg})$ \\
\hline Bitung & 250 & 255 & 210 & 211 & $139.712 .244,76$ \\
\hline Tahuna & 205 & 206 & 270 & 272 & $10.402 .581,00$ \\
\hline Siau & 189 & 205 & 271 & 270 & 2.199.932,00 \\
\hline $\begin{array}{c}\text { Beo } \\
\text { Melong } \\
\text { Lirung }\end{array}$ & 205 & 204 & 220 & 271 & $8.521 .537,00$ \\
\hline Kotamobagu & 271 & 270 & 162 & 189 & $20.250 .907,35$ \\
\hline \multirow[t]{2}{*}{ Demand(Kg) } & 1.644 .660 & 458.280 & 1.101 .960 & 788.400 & \\
\hline & \multicolumn{4}{|c|}{ Tarif Angkut Raskin (Rp/Kg) } & \\
\hline Darike & Bolmut & Bolsel & Bolmong & & $\operatorname{Supply}(\mathbf{K g})$ \\
\hline Bitung & 211 & 213 & 210 & & $139.712 .244,76$ \\
\hline Tahuna & 275 & 271 & 203 & & $10.402 .581,00$ \\
\hline Siau & 275 & 276 & 273 & & $2.199 .932,00$ \\
\hline $\begin{array}{c}\text { Beo } \\
\text { Melong } \\
\text { Lirung } \\
\end{array}$ & 277 & 276 & 275 & & $8.521 .537,00$ \\
\hline Kotamobagu & 204 & 200 & 168 & & $20.250 .907,35$ \\
\hline Demand(Kg) & 853.020 & 1.004 .400 & 3.405 .420 & & \\
\hline
\end{tabular}

Dari data pada tabel 4, kemudian diformulasikan ke dalam bentuk matematis yakni sebagai berikut:

Fungsi tujuan 


$$
\begin{aligned}
\text { Min } \mathrm{Z}=162 \mathrm{X}_{11} & +204 \mathrm{X}_{12}+162 \mathrm{X}_{13}+189 \mathrm{X}_{14} \\
& +168 \mathrm{X}_{15}+200 \mathrm{X}_{16}+162 \mathrm{X}_{17} \\
& +250 \mathrm{X}_{18}+250 \mathrm{X}_{19} \\
& +255 \mathrm{X}_{110}+210 \mathrm{X}_{111} \\
& +211 \mathrm{X}_{112}+211 \mathrm{X}_{113} \\
& +213 \mathrm{X}_{14}+210 \mathrm{X}_{115} \\
& +250 \mathrm{X}_{21}+265 \mathrm{X}_{22}+250 \mathrm{X}_{23} \\
& +265 \mathrm{X}_{24}+250 \mathrm{X}_{25}+260 \mathrm{X}_{26} \\
& +250 \mathrm{X}_{27}+204 \mathrm{X}_{28}+205 \mathrm{X}_{29} \\
& +206 \mathrm{X}_{210}+270 \mathrm{X}_{211} \\
& +272 \mathrm{X}_{212}+275 \mathrm{X}_{213} \\
& +271 \mathrm{X}_{214}+203 \mathrm{X}_{215} \\
& +245 \mathrm{X}_{31}+255 \mathrm{X}_{32}+245 \mathrm{X}_{33} \\
& +250 \mathrm{X}_{34}+250 \mathrm{X}_{35}+250 \mathrm{X}_{36} \\
& +245 \mathrm{X}_{37}+204 \mathrm{X}_{38}+189 \mathrm{X}_{39} \\
& +205 \mathrm{X}_{310}+271 \mathrm{X}_{311} \\
& +270 \mathrm{X}_{312}+275 \mathrm{X}_{313} \\
& +276 \mathrm{X}_{314}+273 \mathrm{X}_{315} \\
& +223 \mathrm{X}_{41}+240 \mathrm{X}_{42}+255 \mathrm{X}_{43} \\
& +260 \mathrm{X}_{44}+224 \mathrm{X}_{45}+229 \mathrm{X}_{46} \\
& +223 \mathrm{X}_{47}+205 \mathrm{X}_{48}+180 \mathrm{X}_{49} \\
& +204 \mathrm{X}_{410}+220 \mathrm{X}_{411} \\
& +271 \mathrm{X}_{412}+277 \mathrm{X}_{413} \\
& +276 \mathrm{X}_{414}+275 \mathrm{X}_{415} \\
& +210 \mathrm{X}_{51}+206 \mathrm{X}_{52}+208 \mathrm{X}_{53} \\
& +206 \mathrm{X}_{54}+208 \mathrm{X}_{55}+206 \mathrm{X}_{56} \\
& +270 \mathrm{X}_{57}+271 \mathrm{X}_{58}+270 \mathrm{X}_{59} \\
& +220 \mathrm{X}_{510}+162 \mathrm{X}_{511} \\
& +189 \mathrm{X}_{512}+204 \mathrm{X}_{513} \\
& +200 \mathrm{X}_{514}+168 \mathrm{X}_{515} \\
& \\
& \\
& \\
& \\
&
\end{aligned}
$$

\begin{tabular}{|c|c|c|c|}
\hline No & Gudang & Tujuan & $\begin{array}{c}\text { Jumlah } \\
\text { Raskin (Kg) } \\
\end{array}$ \\
\hline \multirow{7}{*}{1} & \multirow{7}{*}{ Bitung } & Manado & 2.892 .060 \\
\hline & & Mitra & 1.627 .020 \\
\hline & & Tomohon & 980.100 \\
\hline & & Minahasa & 3.897 .900 \\
\hline & & $\begin{array}{l}\text { Minahasa } \\
\text { Utara }\end{array}$ & 2.965 .320 \\
\hline & & $\begin{array}{c}\text { Minahasa } \\
\text { Selatan }\end{array}$ & 3.513 .060 \\
\hline & & Bitung & 1.943 .640 \\
\hline 2 & Tahuna & Sangihe & 1.920 .780 \\
\hline 3 & Siau & Sitaro & 1.644 .660 \\
\hline 4 & $\begin{array}{c}\text { Beo } \\
\text { Melonguane } \\
\text { Lirung } \\
\end{array}$ & Talaud & 458.280 \\
\hline \multirow{5}{*}{5} & \multirow{5}{*}{ Kotamobagu } & Kotamobagu & 1.101 .960 \\
\hline & & Boltim & 788.400 \\
\hline & & Bolmut & 853.020 \\
\hline & & Bolsel & 1.004 .400 \\
\hline & & Bolmong & 3.405 .420 \\
\hline
\end{tabular}

dengan batasan

a Kapasitas (gudang):

$X_{11}+X_{12}+X_{13}+X_{14}+X_{15}+X_{16}+$

$X_{17}+X_{18}+X_{19}+X_{110}+X_{111}+X_{112}+$

$X_{13}+X_{114}+X_{115}=139.712 .244,76$

$X_{21}+X_{22}+X_{23}+X_{24}+X_{25}+X_{26}+$

$X_{27}+X_{28}+X_{29}+X_{210}+X_{211}+X_{212}+$

$X_{213}+X_{214}+X_{215}=10.402 .581,00$

$X_{31}+X_{32}+X_{33}+X_{34}+X_{35}+X_{36}+$

$X_{37}+X_{38}+X_{39}+X_{310}+X_{311}+X_{312}+$

$X_{313}+X_{314}+X_{315}=2.199 .932,00$

$X_{41}+X_{42}+X_{43}+X_{44}+X_{45}+X_{46}+$

$X_{47}+X_{48}+X_{49}+X_{410}+X_{411}+X_{412}+$

$X_{413}+X_{414}+X_{415}=8.521 .537,00$

$X_{51}+X_{52}+X_{53}+X_{54}+X_{55}+X_{56}+$

$X_{57}+X_{58}+X_{59}+X_{510}+X_{511}+X_{512}+$ $X_{513}+X_{514}+X_{515}=20.250 .907,35$

b Permintaan (tujuan):

$\mathrm{X}_{11}+\mathrm{X}_{21}+\mathrm{X}_{31}+\mathrm{X}_{41}+\mathrm{X}_{51}=2.892 .060$

$\mathrm{X}_{12}+\mathrm{X}_{22}+\mathrm{X}_{32}+\mathrm{X}_{42}+\mathrm{X}_{52}=1.627 .020$

$\mathrm{X}_{13}+\mathrm{X}_{23}+\mathrm{X}_{33}+\mathrm{X}_{43}+\mathrm{X}_{53}=980.100$

$$
\begin{aligned}
& X_{14}+X_{24}+X_{34}+X_{44}+X_{54}=3.897 .900 \\
& X_{15}+X_{25}+X_{35}+X_{45}+X_{55}=2.965 .320 \\
& X_{16}+X_{26}+X_{36}+X_{46}+X_{56}=3.513 .060 \\
& X_{17}+X_{27}+X_{37}+X_{47}+X_{57}=1.943 .640 \\
& X_{18}+X_{28}+X_{38}+X_{48}+X_{58}=1.920 .780 \\
& X_{18}+X_{29}+X_{39}+X_{49}+X_{59}=1.644 .660 \\
& X_{110}+X_{210}+X_{310}+X_{410}+ \\
& X_{510}=458.280 \\
& X_{111}+X_{211}+X_{311}+X_{411}+ \\
& X_{511}=1.101 .960 \\
& X_{112}+X_{212}+X_{312}+X_{412}+ \\
& X_{512}=788.400 \\
& X_{113}+X_{213}+X_{313}+X_{413}+ \\
& X_{513}=853.020 \\
& X_{114}+X_{214}+X_{314}+X_{414}+ \\
& X_{514}=1.004 .400 \\
& X_{115}+X_{215}+X_{315}+X_{415}+ \\
& X_{515}=3.405 .420
\end{aligned}
$$

Tabel 5 Jumlah Raskin Yang Harus Disalurkan

\section{Analisis Data dengan Menggunakan Program Riset Operasi}

Berikut ini merupakan hasil output berdasarkan analisis dengan bantuan 
program riset operasi menggunakan metode pendekatan vogel. Terdapat enam output yang dihasilkan dari penyelesaian hasil analisis.

\section{Transportation Shipments}

Transportation Shipments menjelaskan mengenai jumlah raskin yang harus dialokasikan dari 5 gudang (Bitung, Tahuna, Siau, Beo-Melonguane-Lirung, dan Kotamobagu) ke 15 tujuan agar mendapatkan biaya distribusi yang optimal. Jumlah raskin yang disalurkan sebagaimana pada tabel 5 .

2. Marginal Cost

Marginal cost menunjukan bahwa biaya tambahan yang terjadi apabila Perusahaan bulog Sulawesi Utara dan Gorontalo melakukan alokasi penyaluran beras miskin dari 5 gudang (Bitung, Tahuna, Siau,BeoMelonguane-Lirung, Kotamobagu) ke 15 tujuan tidak sesuai dengan tabel solusi. Biaya tambahan untuk per kilogram raskinnya sebagaimana pada tabel 6 .

\section{Final Solution Table}

Final Solution Table menunjukan besarnya alokasi pendistribusian beras miskin dari 5 gudang ( Bitung, Tahuna, Siau, BeoMelonguane-Lirung) ke 15 daerah tujuan beserta dengan biaya tambahannya (Marginal Cost). Dimana dengan bantuan program riset operasi besarnya alokasi raskin ditunjukan oleh angka berwarna biru, sedangkan biaya tambahan (Marginal Cost) apabila perusahaan umum badan urusan logistik memaksakan alokasi yang tidak sesuai ditunjukan oleh angka yang bertanda kurung (berwarna ungu). Untuk mempermudah dalam pengamatan terhadap biaya tambahan (marginal cost) dan besar alokasi raskin di perusahaan umum badan urusan logistik divisi regional Sulawesi Utara dan Gorontalo selama tahun 2016, seluruh data marginal cost beserta besar alokasi raskin ditampilkan sebagaimana pada tabel 7 .

4. Iterasi

Output iterasi menunjukan iterasi yang merupakan tahap perhitungan manual hingga memperoleh solusi optimal. Pada kasus ini terdapat 8 kali iterasi sampai ditemukannya solusi optimal.
Tabel. 6 Biaya Tambahan Beras Miskin

\begin{tabular}{|c|c|c|c|c|}
\hline & \multicolumn{4}{|c|}{ Biaya Tambahan (Rp/Kg) } \\
\hline Dari/ke & Manado & Mitra & Tomohon & Minahasa \\
\hline \multicolumn{5}{|l|}{ Bitung } \\
\hline Tahuna & 88 & 61 & 88 & 76 \\
\hline Siau & 83 & 51 & 83 & 61 \\
\hline $\begin{array}{c}\text { Beo } \\
\text { Melonguane } \\
\text { Lirung } \\
\end{array}$ & 61 & 36 & 93 & 71 \\
\hline \multirow[t]{2}{*}{ Kotamobagu } & 48 & 2 & 46 & 17 \\
\hline & \multicolumn{4}{|c|}{ Biaya Tambahan $(\mathrm{Rp} / \mathrm{Kg})$} \\
\hline Dari/ke & Minut & Minsel & Bitung & Sangihe \\
\hline Bitung & & & & 46 \\
\hline Tahuna & 82 & 60 & 88 & \\
\hline Siau & 82 & 50 & 83 & \\
\hline $\begin{array}{c}\text { Beo } \\
\text { Melonguane } \\
\text { Lirung } \\
\end{array}$ & 56 & 29 & 61 & 4 \\
\hline \multirow[t]{2}{*}{ Kotamobagu } & 40 & 6 & 48 & 66 \\
\hline & \multicolumn{4}{|c|}{ Biaya Tambahan $(\mathrm{Rp} / \mathrm{Kg})$} \\
\hline Dari/ke & Sitaro & Talaud & Kota & Boltim \\
\hline Bitung & 61 & 51 & 48 & 22 \\
\hline Tahuna & 16 & 2 & 108 & 83 \\
\hline Siau & & 1 & 109 & 81 \\
\hline $\begin{array}{c}\text { Beo } \\
\text { Melonguane } \\
\text { Lirung } \\
\end{array}$ & 16 & & 58 & 82 \\
\hline \multirow[t]{2}{*}{ Kotamobagu } & 82 & 66 & & \\
\hline & \multicolumn{3}{|c|}{ Biaya Tambahan $(\mathrm{Rp} / \mathrm{Kg})$} & \\
\hline Dari/ke & Bolmut & Bolsel & Bolmong & \\
\hline Bitung & 7 & 13 & 42 & \\
\hline Tahuna & 71 & 71 & 35 & \\
\hline Siau & 71 & 76 & 105 & \\
\hline $\begin{array}{c}\text { Beo } \\
\text { Melonguane } \\
\text { Lirung }\end{array}$ & 73 & 76 & 107 & \\
\hline Kotamobagu & & & & \\
\hline
\end{tabular}

\section{Shipments with cost}

Output Shipments with cost menunjukan besarnya alokasi raskin dan biaya yang dibutuhkan perusahaan umum badan urusan logistik Sulawesi Utara dan Gorontalo untuk pengalokasian tersebut. Besarnya alokasi raskin dan biaya yang dibutuhkan perusahaan sebagaimana pada tabel 8 .

\section{Shipping List}

Shipments with costs merupakan tabel yang menunjukkan besarnya alokasi dan biaya yang diperlukan untuk pengalokasian tersebut (Leony dkk, 2017). Dalam penelitian ini Shipping List menunjukan mengenai seluruh rincian pengalokasian raskin di Sulawesi Utara dari 5 gudang (Birung, Tahuna, Siau, 
Beo-Melonguane-Lirung) ke 15 daerah tujuan beserta dengan biaya per kilogram raskin, dan total biaya tiap pengalokasian raskin. Seluruh rincian besar alokasi raskin dan biaya yang dibutuhkan sebagaimana pada tabel 9.

Tabel.7 Final Solution Tabel

\begin{tabular}{|c|c|c|c|c|}
\hline & \multicolumn{4}{|c|}{ Besar Alokasi $(K g)$ dan Biaya Tambahan (Rp/Kg) } \\
\hline Dari/ke & Manado & Mitra & Tomohon & Minahasa \\
\hline Bitung & 2.892.060 & 1.627.020 & 980.100 & 3.897 .900 \\
\hline Tahuna & [88] & [61] & [88] & [76] \\
\hline Siau & [83] & [51] & [83] & [61] \\
\hline $\begin{array}{c}\text { Beo } \\
\text { Melonguane } \\
\text { Lirung } \\
\end{array}$ & [61] & [36] & [93] & [71] \\
\hline \multirow[t]{2}{*}{ Kotamobagu } & [48] & [2] & [46] & [17] \\
\hline & \multicolumn{4}{|c|}{ Besar Alokasi (Kg) dan Biaya Tambahan (Rp/Kg) } \\
\hline Dari/ke & Minut & Minsel & Bitung & Sangihe \\
\hline Bitung & 2.965 .320 & 3.513 .060 & 1.943 .640 & [46] \\
\hline Tahuna & [82] & [60] & [88] & 1.920 .780 \\
\hline Siau & [82] & [50] & [83] & \\
\hline $\begin{array}{c}\text { Beo } \\
\text { Melonguane } \\
\text { Lirung } \\
\end{array}$ & [56] & [29] & [61] & [4] \\
\hline \multirow[t]{2}{*}{ Kotamobagu } & [40] & [6] & [48] & [66] \\
\hline & \multicolumn{4}{|c|}{ Besar Alokasi(Kg) dan Biaya Tambahan (Rp/Kg) } \\
\hline Dari/ke & Sitaro & Talaud & Kota & Boltim \\
\hline Bitung & [61] & [51] & [48] & [22] \\
\hline Tahuna & [16] & [2] & [108] & [83] \\
\hline Siau & 1.644 .660 & [1] & [109] & [81] \\
\hline $\begin{array}{c}\text { Beo } \\
\text { Melonguane } \\
\text { Lirung } \\
\end{array}$ & [16] & 458.280 & [58] & [82] \\
\hline \multirow[t]{2}{*}{ Kotamobagu } & [82] & [66] & 1.101 .960 & 788.400 \\
\hline & \multicolumn{3}{|c|}{ Besar Alokasi $(\mathrm{Kg})$ dan Biaya Tambahan $(\mathrm{Rp} / \mathrm{Kg})$} & \\
\hline Dari/ke & Bolmut & Bolsel & Bolmong & \\
\hline Bitung & [7] & [13] & [42] & \\
\hline Tahuna & [71] & [71] & [35] & \\
\hline Siau & [71] & [76] & [105] & \\
\hline $\begin{array}{c}\text { Beo } \\
\text { Melonguane } \\
\text { Lirung } \\
\end{array}$ & [73] & [76] & [107] & \\
\hline Kotamobagu & 853.020 & 1.004 .400 & 3.405 .420 & \\
\hline
\end{tabular}

Setelah mencoba metode pendekatan vogel, peneliti juga telah mencoba mengujinya dengan menggunakan metode yang lain yaitu northwest corner method dan minimum cost method, dan diperoleh biaya transportasi optimal yang hampir sama yaitu:

1. northwest corner method biaya optimalnya sebesar Rp. 5.282.261.000

2. minimum cost method biaya optimalnya sebesar Rp. 5.282.260.000
Tabel.8 Shipments With Cost

\begin{tabular}{|c|c|c|c|c|}
\hline No & Gudang & Tujuan & $\begin{array}{c}\text { Besar } \\
\text { Alokasi } \\
(\mathbf{K g})\end{array}$ & $\begin{array}{l}\text { Biaya Alokasi } \\
\text { Raskin (Rp) }\end{array}$ \\
\hline \multirow{7}{*}{1} & \multirow{7}{*}{ Bitung } & Manado & 2.892 .060 & 468.513 .700 \\
\hline & & Mitra & 1.627 .020 & 331.912 .100 \\
\hline & & Tomohon & 980.100 & 158.776 .200 \\
\hline & & Minahasa & 3.897 .900 & 736.703 .100 \\
\hline & & $\begin{array}{c}\text { Minahasa } \\
\text { Utara }\end{array}$ & 2.965 .320 & 498.173 .800 \\
\hline & & $\begin{array}{l}\text { Minahasa } \\
\text { Selatan }\end{array}$ & 3.513 .060 & 702.612 .000 \\
\hline & & Bitung & 1.943 .640 & 314.869 .700 \\
\hline 2 & Tahuna & Sangihe & 1.920 .780 & 391.839 .100 \\
\hline 3 & Siau & Sitaro & 1.644 .660 & 310.840 .700 \\
\hline 4 & $\begin{array}{c}\text { Beo } \\
\text { Melonguane } \\
\text { Lirung }\end{array}$ & Talaud & 458.280 & 93.489 .120 \\
\hline \multirow{5}{*}{5} & \multirow{5}{*}{ Kotamobagu } & Kotamobagu & 1.101 .960 & 178.517 .500 \\
\hline & & Boltim & 788.400 & 149.007 .600 \\
\hline & & Bolmut & 853.020 & 174.016 .100 \\
\hline & & Bolsel & 1.004 .400 & 200.878 .400 \\
\hline & & Bolmong & 3.405 .420 & 572.110 .600 \\
\hline
\end{tabular}

\section{KESIMPULAN}

1. Dengan menggunakan metode pendekatan vogel telah diperoleh jalur penyaluran distribusi raskin optimal dan menghasilkan jalur penyaluran raskin yang sama dengan jalur penyaluran raskin asli dari perusahaan, hal ini menunjukan bahwa jalur penyaluran raskin perusahaan selama 2016 sudah tepat dan optimal.

2. Perusahaan Umum Badan Urusan Logistik Divisi Regional Sulawesi Utara dan Gorontalo memiliki perhitungan biaya distribusi raskin selama tahun 2016 sebesar Rp. 5.282.261.280, dengan menggunakan metode pendekatan vogel diperoleh biaya distribusi raskin optimal untuk penyaluran selama tahun 2016 yaitu sebesar Rp. 5.282.259.000. Keduanya memiliki selisih biaya distribusi yang tidak jauh berbeda dan 
dapat dikatakan bahwa biaya distribusi raskin perusahaan sudah optimal.

Tabel. 9 Shipping List

\begin{tabular}{|c|c|c|c|c|c|}
\hline No & Dari & $\mathrm{Ke}$ & $\begin{array}{c}\text { Besar } \\
\text { Alokasi (Kg) }\end{array}$ & $\begin{array}{c}\text { Biaya per } \\
\mathrm{Kg} \\
(\mathrm{Rp} / \mathrm{Kg}) \\
\end{array}$ & $\begin{array}{c}\text { Biaya } \\
\text { Alokasi (Rp) }\end{array}$ \\
\hline \multirow{8}{*}{1} & \multirow{8}{*}{ Bitung } & Manado & 2.892 .060 & 162 & 468.513 .700 \\
\hline & & Mitra & 1.627 .020 & 104 & 331.912 .100 \\
\hline & & Tomohon & 980.100 & 162 & 158.776 .200 \\
\hline & & Minahasa & 3.897 .900 & 189 & 736.703 .100 \\
\hline & & $\begin{array}{c}\text { Minahasa } \\
\text { Utara }\end{array}$ & 2.965 .320 & 168 & 498.173 .800 \\
\hline & & $\begin{array}{l}\text { Minahasa } \\
\text { Selatan }\end{array}$ & 3.513 .060 & 200 & 702.612 .000 \\
\hline & & Bitung & 1.943 .640 & 162 & 314.869 .700 \\
\hline & & Dummy & 121.893 .100 & 0 & 0 \\
\hline \multirow{2}{*}{2} & \multirow{2}{*}{ Tahuna } & Sangihe & 1.920 .780 & 204 & 391.839 .100 \\
\hline & & Dummy & 8.481 .800 & 0 & 0 \\
\hline \multirow{2}{*}{3} & \multirow{2}{*}{ Siau } & Sitaro & 1.644 .660 & 189 & 310.840 .700 \\
\hline & & Dummy & 555.272 & 0 & 0 \\
\hline \multirow{2}{*}{4} & \multirow{2}{*}{$\begin{array}{c}\text { Beo } \\
\text { Melonguane } \\
\text { lirung }\end{array}$} & Talaud & 458.280 & 204 & 93.489 .120 \\
\hline & & Dummy & 8.063 .257 & 0 & 0 \\
\hline \multirow{6}{*}{5} & \multirow{5}{*}{ Kotamobagu } & Kotamobagu & 1.101 .960 & 162 & 178.517 .500 \\
\hline & & Boltim & 788.400 & 189 & 149.007 .600 \\
\hline & & Bolmut & 853.020 & 204 & 174.016 .100 \\
\hline & & Bolsel & 1.004 .400 & 200 & 200.878 .400 \\
\hline & & Bolmong & 3.405 .420 & 168 & 572.110 .600 \\
\hline & & Dummy & 13.097 .720 & 0 & 0 \\
\hline
\end{tabular}

\section{DAFTAR PUSTAKA}

Aminudin, 2005. Prinsip-Prinsip Riset Operasi. Erlangga. Jakarta.

Arifin L.S., M. Paendong, dan Y. Langi. 2017. Implementasi Model Transportasi pada Distribusi LPG (Liquid Petroleum Gas) $3 \mathrm{Kg}$ di Sulawesi Utara. $J d C, \mathbf{1}(\mathbf{6})$

Chase, R., R. Jacobs., and N. Aquilano. 2004. Operations Management for Competitive Advantages $10^{\text {th }}$ Editions. Mc Grawhill. New York.
Heizer., Jay dan Barry render. 2007. Manajemen Operasi. Edisi Kesembilan Buku 1.Salemba empat. Jakarta

Jevi dan Hendy. 2012. Pendistribusian Produk Yang Optimal Dengan Metode Transportasi. Jurnal teknik dan ilmu komputer, 1(4)

Kertiasih Ni Ketut. 2009. Penggunaan Metode Transportasi Dalam Program Linier Untuk Pendistribusian Barang. JPTK, 6(2).

Mulyono, Sri. 2004. Riset Operasi. Lembaga Penerbit Fakultas Ekonomi Universitas Indonesia, Jakarta.

Nelwan C., J. Kekenusa dan Y. Langi. 2013. Optimasi Pendistribusian Air dengan menggunakan Metode Least Cost dan Metode Modified Distribution Jurnal ilmiah sains, 13(1).

Nirwansah H dan Widowati. 2006. Efisiensi Biaya Distribusi dengan Metode Transportasi.FMIPA UNDIP, Semarang.

S. Lolyta., M. Situmorang.,dan Normalina. 2014. Aplikasi metode transportasi dalam optimasi biaya distribusi beras miskin (RASKIN) pada PERUM BULOG Sub Divre Medan. Saintia Matematika, 02(03).

Taha, Hamdy A. 1996. Riset Operasi. Bina Rupa, Jakarta.

Yuwono, B dan Putri Nur. 2007. Bahan Kuliah Riset Operasional. UPN VeteranYogyakarta. Yogyakata. 